\title{
Presence of Low Concentrations of Acetic Acid Improves Fermentations using Saccharomyces cerevisiae \\ Greetham D*
}

School of Biosciences, University of Nottingham, Loughborough, Leics, LE12 5RD, UK

\begin{abstract}
Fermentation of sugars released from lignocellulosic biomass (LCMs) is potentially a sustainable option for the production of bioethanol. LCMs release fermentable hexose sugars and the currently non-fermentable pentose sugars; ethanol yield from lignocellulosic residues is dependent on the efficient conversion of available sugars to ethanol. One of the challenges facing the commercial application for the conversion of lignocellulosic material to ethanol is the presence of inhibitors released by the breakdown of plant cell walls.

Presence of acetic acid is an inevitable side-effect for the release of fermentable sugars from the deconstruction of plant cell walls, increasing temperatures used for the pre-treatment process releases acetic acid from the lignin component of the plant cell wall. Using phenotypic microarray analysis revealed that low concentrations (20 mM) acetic acid augmented metabolic output in yeast for an initial period, however, assays at higher concentrations ( $>50 \mathrm{mM})$ reduced metabolic output.

Fermentations in the presence of acetic acid where characterized by an improved fermentation efficiency in assays containing $20 \mathrm{mM}$ acetic acid compared with control conditions, however, efficiency was reduced in assays using 50 $\mathrm{mM}$ acetic acid. Yeast cells in the presence of $20 \mathrm{mM}$ acetic acid produced less glycerol, and produced more ATP when compared with control conditions or in the presence of $50 \mathrm{mM}$ acetic acid.
\end{abstract}

Keywords: Acetic acid; Yeast; Microarrays; Fermentation; Glycerol; ATP

\section{Introduction}

Short-chain weak organic acids are potent inhibitors of microbial growth and are widely applied as preservatives in food and beverages. Short-chain organic acids also occur as inhibitory compounds in industrial fermentation processes, for example the detrimental effect of acetic acid and on the production of bioethanol from lignocellulosic material in a fermentation using Saccharomyces cerevisiae [1].

Acetic acid is produced by the deacetylation of xylan during pretreatment [2] as well as a by-product of bacterial contamination and a minor product of yeast fermentation [3]. The toxicity of acetic acid and other weak organic acids is $\mathrm{pH}$ dependent, as it is the un-dissociated form which passively enters the yeast cell [4]. Un-dissociated acetic acid that diffuses through the cell membrane will become dissociated intracellularly [5], the degree of dissociation will depend on the cytosolic $\mathrm{pH}$. In order to maintain a constant intracellular $\mathrm{pH}$, protons are transported across the cell membrane through the activity of ATPases [5]. This results in an increase in ATP consumption and addition of acetate to a media has been shown to lower biomass produced [6].

Acetic acid also stimulates Programmed Cell Death (PCD) in yeast cells through a mitochondria specific caspase cascade [7]. This appears to be separate from weak acids causing anion accumulation due to acidification of the cytoplasm through passive diffusion of acetic acid through the cell membranes.

Saccharomyces cerevisiae is currently used for the production of bioethanol; Pre-treatment of lignocellulose to release constituent sugars results in the formation of aromatic and acidic compounds such as acetic acid, formic acid, furfural, Hydroxy-Methyl Furfural (HMF), levulinic acid and vanillin [8] that are detrimental to the growth of $S$. cerevisiae. In addition, fermentations carried out within bioreactors generate additional difficulties, such as osmotic stress due to high sugar levels, elevated heat and increasing ethanol concentrations [9-
11]. Acetic acid is ubiquitous in hydrolysates where hemicellulose and components of the plant cell wall have acetyl groups which can undergo hydrolysis [12-14]. The precise mode of action for many of the inhibitors has yet to be fully determined [15]. Weak acid stress is induced when acetic, formic or levulinic acid is liberated from LCMs, they inhibit yeast fermentations reducing both growth and ethanol production.

Weak acids effect fermentation profiles where at low concentrations weak acids improve fermentation rates with increased ethanol yield, weak acids at low concentrations are believed to stimulate ATP production [16], and under anaerobic conditions ethanol is produced [17]. However, at high concentrations the beneficial stimulation of ATP production is overtaken by the acid stimulating the cell to increase ATPase activity.

Strain selection for the production of ethanol from LCM derived sugars has traditionally involved the use of several assays based on cell growth and division, maintenance of viability in stress tests and fermentation analyses $[18,19]$. Whilst very useful, these approaches are time consuming and interpretations can be subjective [20]. The Phenotypic Microarray (PM) developed by Bochner and colleagues, provides an analogous two-dimensional array technology for

*Corresponding author: Greetham D, School of Biosciences, University of Nottingham, Loughborough, Leics, LE12 5RD, UK, Tel: 440-115-951-66; E-mail: darren.greetham@nottingham.ac.uk

Received October 24, 2014; Accepted December 12, 2014; Published December 12, 2014

Citation: Greetham D. (2014) Presence of Low Concentrations of Acetic Acid Improves Fermentations using Saccharomyces cerevisiae. J Bioprocess Biotech 5: 192 doi: 10.4172/2155-9821.1000192

Copyright: (c) 2014 Greetham D. This is an open-access article distributed under the terms of the Creative Commons Attribution License, which permits unrestricted use, distribution, and reproduction in any medium, provided the original author and source are credited. 
simultaneous analysis of live yeast cell populations in a 96-well micro titre plate format $[21,22]$. Use of be-spoke PM plates have been described previously [1], and how metabolic output relates to growth and production of ethanol $[1,23]$. In this present work, the effect of acetic acid on Saccharomyces cerevisiae NCYC2592 on metabolic output and conversion of sugar into ethanol has been assessed and correlated with acetic acid concentrations in the medium.

\section{Material and Methods}

\section{Yeast strain and growth conditions}

S. cerevisiae NCYC 2592 (www.ncyc.co.uk) was maintained on YPD containing agar containing $10 \mathrm{~g} / \mathrm{L}$ yeast extract, $20 \mathrm{~g} / \mathrm{L}$ peptone, $20 \mathrm{~g} / \mathrm{L}$ glucose, and $20 \mathrm{~g} / \mathrm{L}$ agar.

\section{Phenotypic microarray analysis}

Biolog growth medium was prepared using $0.67 \%(\mathrm{w} / \mathrm{V})$ minimal medium (YNB- Yeast Nitrogen Base) supplemented with mixture of $6 \%(\mathrm{w} / \mathrm{v})$ glucose, $2.6 \mu \mathrm{L}$ of yeast nutrient supplement mixture (NS $\times 48$ - $24 \mathrm{mM}$ Adenine- $\mathrm{HCl}, 4.8 \mathrm{mM} \mathrm{L}$-histidine $\mathrm{HCl}$ monohydrate, $48 \mathrm{mM}$ L-leucine, $24 \mathrm{mM}$ L-lysine- $\mathrm{HCl}, 12 \mathrm{mM}$ L-methionine, 12 $\mathrm{mM}$ L-tryptophan and $14.4 \mathrm{mM}$ uracil), and $0.2 \mu \mathrm{l}$ of dye D (Biolog, USA). Final volume was made up to $30 \mu \mathrm{L}$ using Reverse Osmosis (RO) sterile distilled water and aliquoted into individual wells with varying concentrations of acetic acid or levulinic acid (both prepared as $1 \mathrm{M}$ stock solutions) as required.

The inhibitory effects of $\mathrm{pH}$ was measured via Biolog by adjusting media containing $6 \%$ glucose, $2.8 \%$ YNB to $\mathrm{pH} 5$ with phosphoric acid, acetic acid was then added and the $\mathrm{pH}$ again adjusted using either phosphoric acid or $\mathrm{NaOH}$.

Strains were prepared for inoculation and prepared for the PM assay plates as described previously [1], the plates were then placed in the OmniLog reader and incubated for $96 \mathrm{~h}$ at $30^{\circ} \mathrm{C}$.

The OmniLog reader reads the plates at 15 min intervals, converting the pixel density in each well to a signal value reflecting cell growth and dye conversion. After completion of the run, the signal data was compiled and exported from the Biolog software and compiled using Microsoft Excel. In all cases, a minimum of three replicate PM assay per plate were conducted, and the average of the signal values was used. To ensure that dye reduction was not occurring in the absence of growth, all PM plates were carefully examined following each run.

Effect of acetic acid on logarithmic metabolic output was determined by calculating the time required to double maximal output when cells were in logarithmic phase of metabolic activity. Exit from lag phase was determined by determining when metabolic activity was above 10 redox signal intensity units as wells containing media but no cells can produce a metabolic signal up to 10 . Data representative of triplicate wells run on the same plate.

\section{Budding index}

$10 \mu \mathrm{L}$ of yeast cells were spotted onto $1 \mathrm{~mL}$ of YPD agar on a microscope slide containing acetic acid and single or clustered cells counted at x 20 magnification. Viable cells will start budding and become clumps of cells over time; dead cells remain as single cells. All slides were kept at $30^{\circ} \mathrm{C}$ for 42 hours with cell counts occurring after 18 and 42 hours respectively. All experiments were done in triplicate.

\section{Confirmation of phenotypic microarray results using mini fermentation vessels}

Fermentations were conducted in $180 \mathrm{~mL}$ mini-Fermentation Vessels (FV). Cryopreserved yeast colonies were streaked onto YPD plates and incubated at $30^{\circ} \mathrm{C}$ for $48 \mathrm{hrs}$. Colonies of S. cerevisiae NCYC2592 were used to inoculate $20 \mathrm{~mL}$ of YPD broth and incubated in an orbital shaker at $30^{\circ} \mathrm{C}$ for $24 \mathrm{hrs}$. These were then transferred to $200 \mathrm{~mL}$ of YPD and grown for $48 \mathrm{hrs}$ in a $500 \mathrm{~mL}$ conical flask shaking at $30^{\circ} \mathrm{C}$. Cells were harvested and washed three times with sterile RO water and then re-suspended in $5 \mathrm{~mL}$ of sterile water. For control conditions, $1.5 \times 10^{7}$ cells. $\mathrm{mL}^{-1}$ were inoculated in $99.6 \mathrm{~mL}$ of medium containing $8 \%$ glucose, $2 \%$ peptone, $1 \%$ yeast extract with $0.4 \mathrm{~mL} \mathrm{RO}$ water. For stress conditions, $1.5 \times 10^{7}$ cells. $\mathrm{mL}^{-1}$ were incubated in 99.6 $\mathrm{mL}$ of medium containing $8 \%$ glucose, $2 \%$ peptone, $1 \%$ yeast extract with $0-50 \mathrm{mM}$ acetic acid. Volumes of media were adjusted to account for the addition of the inhibitory compounds $(0-400 \mu \mathrm{L})$ to ensure that all fermentations began with the same carbon load.

Anaerobic conditions were prepared using a sealed butyl plug (Fisher, Loughborough, UK) and aluminium caps (Fisher Scientific). A hypodermic needle attached with a Bunsen valve was purged through rubber septum to facilitate the release of $\mathrm{CO}_{2}$. All experiments were performed in triplicate and weight loss was measured at each time point. Mini-fermentations were conducted at $30^{\circ} \mathrm{C}$, with orbital shaking at $200 \mathrm{rpm}$.

Determination of glucose, acetic acid, glycerol and ethanol concentrations from fermentation experiments via HPLC

Glucose, acetic acid, glycerol and ethanol were quantified by HPLC. The HPLC system included a Jasco AS-2055 Intelligent auto sampler (Jasco, Tokyo, Japan) and a Jasco PU-1580 Intelligent pump (Jasco). The chromatographic separation was performed on a Rezex ROA H+ organic acid column, $5 \mu \mathrm{m}, 7.8 \mathrm{~mm} \times 300 \mathrm{~mm}$, (Phenomenex, Macclesfield, UK) at ambient temperature. The mobile phase was $0.005 \mathrm{~N} \mathrm{H}_{2} \mathrm{SO}_{4}$ with a flow rate of $0.5 \mathrm{~mL} / \mathrm{min}$. For detection a Jasco RI-2031 Intelligent refractive index detector (Jasco) was employed. Data acquisition was via the Azur software (version 4.6.0.0, Datalys, St Martin D'heres, France) and concentrations were determined by peak area comparison with injections of authentic standards. The injected volume was $10 \mu \mathrm{l}$ and analysis was completed in 28 minutes. All chemicals used were analytical grade ( $>95 \%$ purity, Sigma-Aldrich, UK).

\section{ATP concentration}

Determination of ATP was using a ATP assay kit (ab8335, Abcam, $\mathrm{UK}$ ), yeast cell pellets (106 cells $/ \mathrm{mL}$ ) taken during the fermentation were then broken using a MagNA lyser (Roche Applied Science, UK), cells were subjected to vigorous shaking/vortexing via the MagNa lyser for $1 \mathrm{~min}$ and repeated five times at a speed of 7,000 rpm while temperature was kept as low as practicable. ATP concentrations were determined using a using a Tecan (Mannedorf, Switzerland) Infinite M200 Pro plate reader at $570 \mathrm{~nm}$.

\section{Statistical analysis}

Data derived from phenotypic microarrays was analysed for analysis of variance (ANOVA) using ezANOVA (http://www.cabiatl. com/mricro/ezanova), a free for use online statistical program with statistical significance signified by use of ${ }^{*},{ }^{*}=0.05 \%$ significant, ${ }^{* *}=$ $0.01 \%$ significant and ${ }^{* * *} 0.001 \%$ significant. 
Citation: Greetham D. (2014) Presence of Low Concentrations of Acetic Acid Improves Fermentations using Saccharomyces cerevisiae. J Bioprocess Biotech 5: 192 doi: 10.4172/2155-9821.1000192

Page 3 of 5

\section{Results}

\section{Presence of acetic acid influences metabolic output in S.} cerevisiae

Presence of acetic acid (0-100 mM) on metabolic output was assessed with a reduction in metabolic output observed at $75 \mathrm{mM}$ acetic acid and no metabolic output observed in an assay containing $100 \mathrm{mM}$ acetic acid (Figure 1A). Low concentrations of acetic acid $(<20 \mathrm{mM})$ had little or no effect on metabolic output when compared with the control (control defined as absence of acetic acid); however, assays containing low concentrations of acetic acid outperformed the unstressed control for the first 8 hours of the experiment $(\mathrm{p}=0.034)$ (Figures 1B and 1C). Augmentation of metabolic output observed for acetic acid was not observed for other weak acids, metabolic output in the presence of levulinic acid failed to show an early augmentation at low concentrations of levulinic acid $(\mathrm{p}=0.54)$ (Figure 1D). $\mathrm{pH}$ for all experiments was adjusted to $\mathrm{pH} 5$ following the addition of acetic or levulinic acid with the addition of $\mathrm{NaOH}$ or phosphoric acid as appropriate.

Using metabolic output data and determining when the cell exits lag phase and enters logarithmic phase of metabolic output allows us to investigate how long a cell takes to overcome acetic acid stress. Plotting acetic acid concentration against entry into logarithmic metabolic output revealed that increasing concentrations of acetic acid increased the length of time the yeast takes to enter into log phase of metabolic output (Figure 2A). Presence of acetic acid also reduced maximal rates of metabolic output when compared with unstressed controls (Figure 2B).

\section{Presence of acetic acid slows conversion of metabolic output into cell mass}

Measuring yeast growth in the presence of acetic acid shows a correlation between concentration of acetic acid and growth. Presence of low concentrations of acetic acid (10-25 mM) had little or no impact on growth, indeed growth in the presence of $25 \mathrm{mM}$ acetic acid was improved with unstressed controls (Figure 3A). Increasing acetic acid to $50 \mathrm{mM}$ slowed growth, characterised by a longer lag phase and a delay of entry into the exponential growth phase (Figure 3A). Comparing growth (OD600) and metabolic output (redox signal intensity) revealed that under control conditions there was no difference between rates of growth and metabolic output (Figure 3B), however, in the presence of $50 \mathrm{mM}$ acetic acid there is a delay between metabolic output and cellular growth (Figure 3C).

An assessment of the number of budding cells after 18 and 42 hours exposure (these time points were chosen because after 18 hours yeast are principally in logarithmic phase of metabolic output but after 42 hours have reached stationary phase of metabolic output (Figure 1A)) observed a reduction in budding cells in the presence of acetic acid after 18 hours (10-50 $\mathrm{mM}$ ) when compared with control conditions. However, after 42 hours in the presence of 10-30 mM the number of budding index had returned to unstressed control conditions (Figure $2 \mathrm{~F}$ ).

\section{There was no increase in acetic acid toxicity at $\mathrm{pH} 4$ or $\mathrm{pH} 7$}

Toxicity of acetic acid is closely related to the $\mathrm{pH}$ of the media as the concentrations of un-dissociated form increases as the $\mathrm{pH}$ of the media decreases [4], initial studies were performed at $\mathrm{pH} \mathrm{5}$, however we also assayed for the toxicity of low concentrations $(10-25 \mathrm{mM})$ at $\mathrm{pH} 4$ and $\mathrm{pH}$ 7. Assays revealed that there was no inhibition caused by the presence of acetic acid at either $\mathrm{pHs}$ when compared with controls in which the $\mathrm{pH}$ had been set using phosphoric acid (Figures $4 \mathrm{~A}$ and $4 \mathrm{~B}$ ), indicating that the presence of low concentrations of acetic acid was not inhibitory at $\mathrm{pH}$ 4-7 when compared with assays just looking at the effect of $\mathrm{pH}$.

\section{Presence of $20 \mathrm{mM}$ acetic acid improves ethanol production during fermentation}

Presence of $20 \mathrm{mM}$ acetic acid on ethanol and glycerol production was assessed and compared with unstressed control conditions during fermentations. Ethanol production in the presence of acetic acid was higher $(43.58 \pm 0.53 \mathrm{~g} / \mathrm{L})$ than under control conditions $(41.04 \pm 0.46)$ (Table 1), the theoretical maxima for glucose to ethanol conversion is $0.51 \mathrm{~g} / \mathrm{L}$ [24] with an improved fermentation efficiency $93.53 \%$ compared with $88.82 \%$ (Table 1). Assessment of glycerol revealed that there was a reduction in glycerol production in the presence of acetic acid $(2.78 \pm 0.03 \mathrm{~g} / \mathrm{L})$ compared with control conditions $(4.19$ $\pm 0.045 \mathrm{~g} / \mathrm{L}$ ) (Table 1). Fermentations in the presence of $50 \mathrm{mM}$ acetic acid where characterised by a reduced ethanol production $(34.45 \pm 0.4$ $\mathrm{g} / \mathrm{L}$ ), reduced fermentation efficiency $78.31 \%$ and a reduced glycerol production $(1.78 \pm 0.2 \mathrm{~g} / \mathrm{L})$ (Table 1$)$

\section{ATP levels increased in the presence of low concentrations of acetic acid}

ATP concentrations have been shown to be increased at relatively low concentrations of acetic acid; we measured ATP concentrations in the presence of acetic acid throughout fermentations. ATP concentrations under control conditions at the start of the fermentation was determined to be $0.04 \pm 0.003 \mathrm{mM}$ and increased for the first eight hours of the fermentation to a peak of $0.09 \pm 0.004 \mathrm{mM}$ before decreasing to $0.06 \pm 0.001 \mathrm{mM}$ for the remainder of the fermentation (Table 2). Addition of $20 \mathrm{mM}$ acetic acid stimulated ATP production for the first 8 hours of the fermentation $(0.15 \pm 0.04 \mathrm{mM})$ subsequently there was no increase in ATP production observed for the duration of
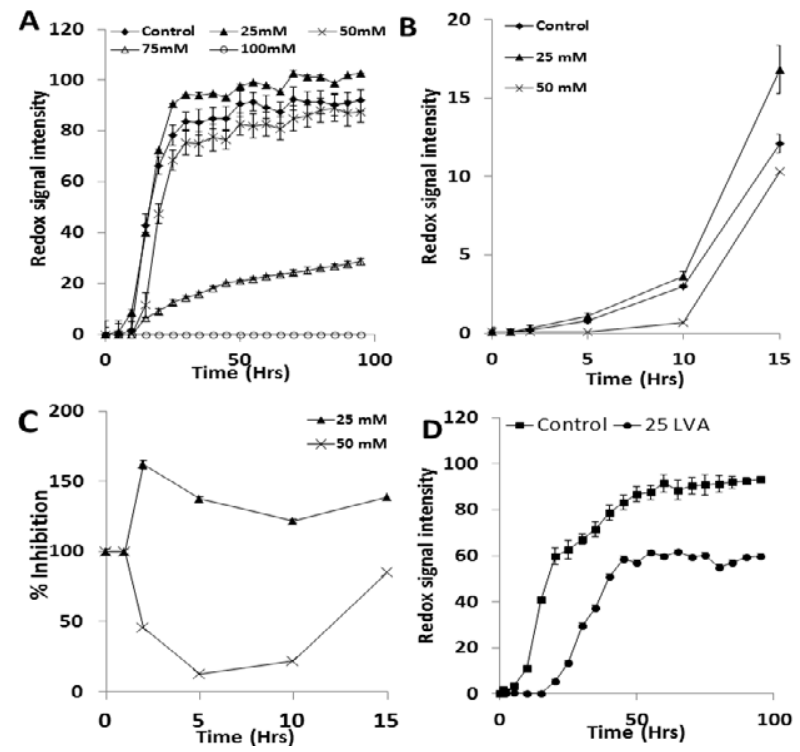

Figure 1: (A) Metabolic output under 0-100 mM acetic acid for $S$. cerevisiae NCYC2592, (B) metabolic output for 0-50 mM acetic acid for S. cerevisiae NCYC2592 for $0-15 \mathrm{hrs},(\mathrm{C}) \%$ inhibition of metabolic output in the presence of 25 and $50 \mathrm{mM}$ acetic acid when compared with under control conditions, (D) metabolic output under 0-25 mM levulinic acid for $S$. cerevisiae NCYC2592. Data representative of triplicate values (Mean $S D=3$ ). 
Citation: Greetham D. (2014) Presence of Low Concentrations of Acetic Acid Improves Fermentations using Saccharomyces cerevisiae. J Bioprocess Biotech 5: 192 doi: 10.4172/2155-9821.1000192

Page 4 of 5
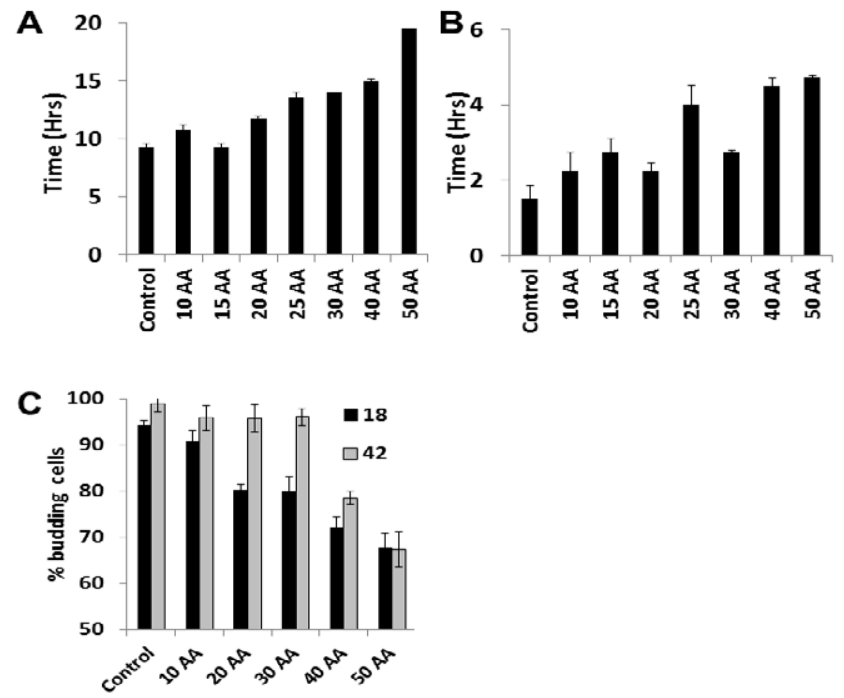

Figure 2: (A) effect of acetic acid $(0-50 \mathrm{mM})$ on exit of lag phase of metabolic output, (B) effect of acetic acid $(0-50 \mathrm{mM})$ on maximal metabolic output, (D) comparison of yeast growth and metabolic output under control conditions, $(\mathrm{E})$ comparison of growth and metabolic output in the presence of $50 \mathrm{mM}$ acetic acid and (C) budding index in the presence of acetic acid (0-50 $\mathrm{mM})$ after 18 and 42 hours exposure respectively. Data representative of triplicate values (Mean $\mathrm{SD}=3$ ).
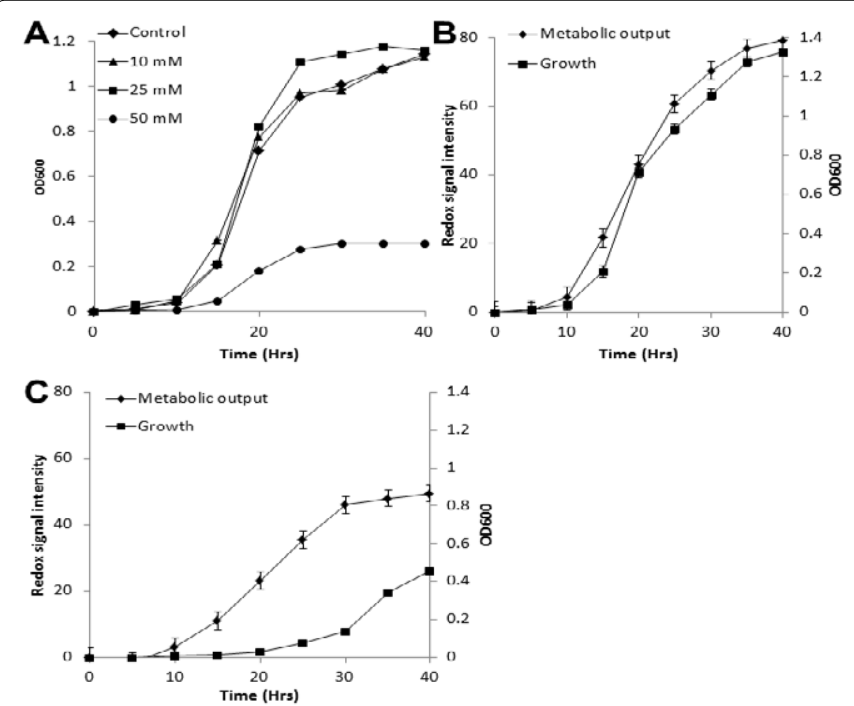

Figure 3: (A) Growth (OD600) under 0-50 mM acetic acid (B) comparison of growth and metabolic output under control conditions, (C) comparison of growth and metabolic output in the presence of $50 \mathrm{mM}$ acetic acid. Data representative of triplicate values (Mean $\mathrm{SD}=3$ ).

the fermentation $(\mathrm{p}=0.08)$ (Table 2). Addition of $50 \mathrm{mM}$ acetic acid was characterised by no increase in ATP production for the first 10 hours of the fermentation before an increase was observed (Table 2). ATP concentrations in fermentations in the presence of $50 \mathrm{mM}$ acetic acid did not increase above that observed under control conditions for any time point measured during the fermentation $(\mathrm{p}=0.91)$ (Table 2$)$.

\section{Discussion}

Presence of acetic acid is an unavoidable consequence of the pretreatment of lignocellulosic material as lignocellulosic material contains hemicellulose which reinforces the plant cell wall [25]. Regardless of the lignocellulosic material, a structural component of hemicellulose is that some of the pyranose subunits are substituted for acetyl groups [26], upon treatment for the liberation of monomeric sugars acetic acid is generated from the degradation of acetylated sugars with concentrations present at $1-10 \mathrm{~g} / \mathrm{L}$ [27].

Presence of acetic acid at higher concentrations is inhibitory, however, assays at sub-lethal concentrations $(10-20 \mathrm{mM})$ improves metabolic output, rates of fermentation and ethanol production. Acetic acid remains unchanged throughout the fermentation, however, at lower concentrations there is lower glycerol production and higher ATP levels within the cell when compared with unstressed conditions. Increasing acetic acid concentrations is characterised by a slower rate of fermentation and a reduced conversion of glucose into ethanol with increased glycerol production and reduced ATP production.

Presence of acetic acid (20-80 mM) has been shown to induce Programmed Cell Death (PCD) [28], either involving mitochondria (intrinsic pathway) or a pathway involving cytosolic caspases called the extrinsic pathway $[29,30]$. The toxicity of acetic acid is $\mathrm{pH}$ dependent, acetic acid in its un-dissociated form diffuses through the cell membrane and dissociation is dependent on cytosolic $\mathrm{pH}$, however, at low acetic acid concentrations $(<20 \mathrm{mM})$ there was no increase in toxicity in the presence of acetic acid compared with $\mathrm{pH}$ adjusted assays.

Fermentations in the presence of $20 \mathrm{mM}$ acetic acid were characterised by an increase in fermentation efficiency, a reduction in glycerol production and an increase in ATP production. An increase in ATP production and a reduction in glycerol production has been
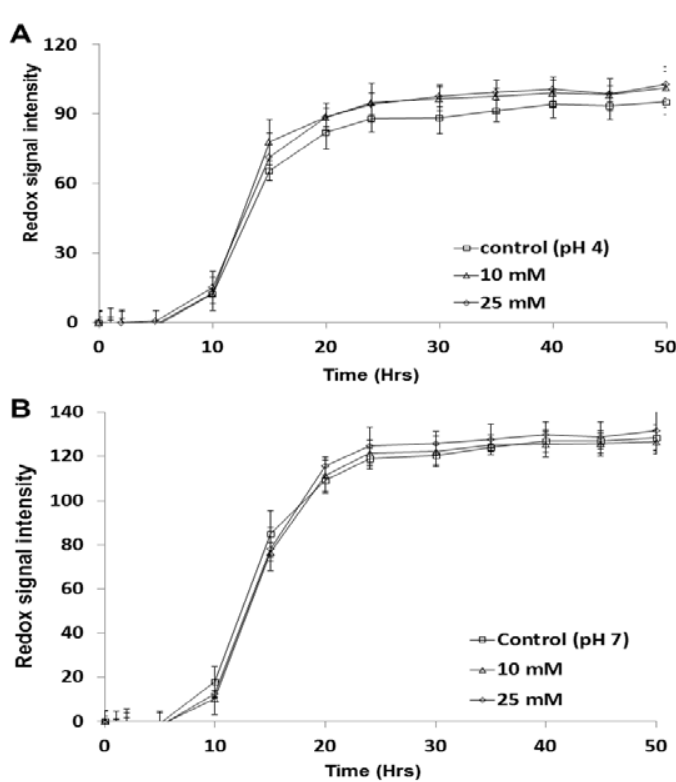

Figure 4: (A) Effect of 0,10 and $25 \mathrm{mM}$ acetic acid on metabolic output at $\mathrm{pH} 4$, (B) Effect of 0,10 and $25 \mathrm{mM}$ acetic acid on metabolic output at $\mathrm{pH}$ 7. Data representative of triplicate values (Mean $\mathrm{SD}=3$ ).

\begin{tabular}{|c|c|c|c|}
\hline Acetic acid (mM) & Ethanol (g/L) & Glycerol (g/L) & Fermentation Efficiency (\%) \\
\hline 0 & $41.04 \pm 0.46$ & $4.19 \pm 0.045$ & 88.82 \\
\hline 20 & $43.58 \pm 0.53$ & $2.78 \pm 0.03$ & 93.53 \\
\hline 50 & $34.45 \pm 0.4$ & $1.78 \pm 0.2$ & 78.31 \\
\hline
\end{tabular}

Table 1: Ethanol, glycerol production (g/L) for S. cerevisiae NCYC2592 under control conditions (no acetic acid), $20 \mathrm{mM}$ and $50 \mathrm{mM}$ acetic acid. Fermentation efficiencies (\%) were calculated using ethanol production- $0.51 \mathrm{~g} / \mathrm{L}$ theoretical maxima. 
Citation: Greetham D. (2014) Presence of Low Concentrations of Acetic Acid Improves Fermentations using Saccharomyces cerevisiae. J Bioprocess Biotech 5: 192 doi: 10.4172/2155-9821.1000192

Page 5 of 5

\begin{tabular}{|c|c|c|c|}
\hline \multirow{2}{*}{ Time (Hrs) } & \multicolumn{3}{|c|}{ ATP concentration (mM) } \\
\cline { 2 - 4 } & Control & $\mathbf{2 0 ~} \mathbf{~ m M}$ acetic acid & $\mathbf{5 0} \mathbf{~ m M}$ acetic acid \\
\hline 0 & $0.04 \pm 0.003$ & $0.04 \pm 0.003$ & $0.04 \pm 0.003$ \\
\hline 2 & $0.06 \pm 0.004$ & $0.08 \pm 0.007$ & $0.05 \pm 0.001$ \\
\hline 4 & $0.08 \pm 0.001$ & $0.09 \pm 0.008$ & $0.05 \pm 0.001$ \\
\hline 6 & $0.09 \pm 0.006$ & $0.10 \pm 0.009$ & $0.05 \pm 0.002$ \\
\hline 8 & $0.09 \pm 0.004$ & $0.12 \pm 0.004$ & $0.05 \pm 0.004$ \\
\hline 10 & $0.08 \pm 0.001$ & $0.15 \pm 0.001$ & $0.07 \pm 0.003$ \\
\hline 12 & $0.07 \pm 0.005$ & $0.15 \pm 0.007$ & $0.06 \pm 0.001$ \\
\hline
\end{tabular}

Table 2: ATP concentrations for $S$. cerevisiae NCYC2592 at selected time points during fermentation in the presence of acetic acid (0-50 mM). Data representative of triplicate values (Mean $\mathrm{SD}=3$ )

shown previously for yeast cells under acetic acid stress [16], glycerol is one of the main by-products in an ethanol fermentation and may account for $5 \%$ of the available carbon [31], reducing glycerol has been shown to increase ethanol production in an ethanol fermentation [32]. ATP levels for yeast cells under higher concentrations of acetic acid have been shown to be reduced along with inhibition of nutrient uptake when compared with controls [33].

Results here have revealed that presence of relatively low concentrations of acetic acid improve ethanoic fermentations with concurrent reduced accumulation of glycerol and increased ATP production, however, at higher concentrations of acetic acid these effects are reversed.

\section{Acknowledgements}

The research reported here was supported (in full or in part) by the Biotechnology and Biological Sciences Research Council (BBSRC) Sustainable Bioenergy Centre (BSBEC), under the programme for 'Lignocellulosic Conversion to Ethanol' (LACE) [Grant Ref: BB/G01616X/1]. This is a large interdisciplinary programme and the views expressed in this paper are those of the authors alone, and do not necessarily reflect the views of the collaborators or the policies of the funding bodies. This project is part financed by the European Regional Development Fund project EMX05568.

\section{References}

1. Greetham D, Wimalasena T, Kerruish DW, Brindley S, Ibbett RN, et al. (2014) Development of a phenotypic assay for characterisation of ethanologenic yeast strain sensitivity to inhibitors released from lignocellulosic feedstocks. J Ind Microbiol Biotechnol 41: 931-945.

2. Palmqvist E, Hahn-Hägerdal B (2000) Fermentation of lignocellulosic hydrolysates. II: inhibitors and mechanisms of inhibition. Bioresource Technology 74: 25-33.

3. Thomas KC, Hynes SH, Ingledew WM (2002) Influence of medium buffering capacity on inhibition of Saccharomyces cerevisiae growth by acetic and lactic acids. Appl Environ Microbiol 68: 1616-1623.

4. Atkins P, Julio de Paula (2002) Chemical equilbrium. Oxford University Press, 7: 222-251.

5. Mollapour M, Shepherd A, Piper PW (2008) Novel stress responses facilitate Saccharomyces cerevisiae growth in the presence of the monocarboxylate preservatives. Yeast 25: 169-177.

6. Verduyn C, Postma E, Scheffers WA, van Dijken JP (1990) Energetics of Saccharomyces cerevisiae in anaerobic glucose-limited chemostat cultures. J Gen Microbiol 136: 405-412.

7. Madeo F, Herker E, Wissing S, Jungwirth H, Eisenberg T, et al. (2004) Apoptosis in yeast. Curr Opin Microbiol 7: 655-660.

8. Tomás-Pejó E, Oliva JM, Ballesteros M, Olsson L (2008) Comparison of SHF and SSF processes from steam-exploded wheat straw for ethanol production by xylose-fermenting and robust glucose-fermenting Saccharomyces cerevisiae strains. Biotechnol Bioeng 100: 1122-1131.

9. Casey GP, Ingledew WM (1986) Ethanol tolerance in yeasts. Crit Rev Microbiol 13: $219-280$
10. Aslankoohi E, Zhu B, Rezaei MN, Voordeckers K, De Maeyer D, et al. (2013) Dynamics of the Saccharomyces cerevisiae transcriptome during bread dough fermentation. Appl Environ Microbiol 79: 7325-7333.

11. Beltran G, Torija MJ, Novo M, Ferrer N, Poblet M, et al. (2002) Analysis of yeast populations during alcoholic fermentation: a six year follow-up study. Syst Appl Microbiol 25: 287-293.

12. Taherzadeh MJ, Karimi K (2008) Pretreatment of lignocellulosic wastes to improve ethanol and biogas production: a review. Int J Mol Sci 9: 1621-1651.

13. Zhang J, Zhang WX, Wu ZY, Yang J, Liu YH, et al. (2013) A comparison of different dilute solution explosions pretreatment for conversion of distillers' grains into ethanol. Prep Biochem Biotechnol 43: 1-21.

14. Cantarella M, Cantarella L, Gallifuoco A, Spera A, Alfani F (2004) Effect of inhibitors released during steam-explosion treatment of poplar wood on subsequent enzymatic hydrolysis and SSF. Biotechnol Prog 20: 200-206.

15. Mira NP, Teixeira MC, Sá-Correia I (2010) Adaptive response and tolerance to weak acids in Saccharomyces cerevisiae: a genome-wide view. OMICS 14 525-540.

16. Pampulha ME, Loureiro-Dias MC (2000) Energetics of the effect of acetic acid on growth of Saccharomyces cerevisiae. FEMS Microbiol Lett 184: 69-72.

17. Taherzadeh MJ, Lidén G, Gustafsson L, Niklasson C (1996) The effects of pantothenate deficiency and acetate addition on anaerobic batch fermentation of glucose by Saccharomyces cerevisiae. Appl Microbiol Biotechnol 46: 176-182.

18. Attfield PV, Bell PJ (2006) Use of population genetics to derive nonrecombinant Saccharomyces cerevisiae strains that grow using xylose as a sole carbon source. FEMS Yeast Res 6: 862-868.

19. Watanabe I, Ando A, Nakamura T (2012) Characterization of Candida sp. NY7122, a novel pentose-fermenting soil yeast. J Ind Microbiol Biotechnol 39 307-315.

20. Deák T (1993) Simplified techniques for identifying foodborne yeasts. Int J Food Microbiol 19: 15-26.

21. Bochner BR, Gadzinski P, Panomitros E (2001) Phenotype microarrays for high-throughput phenotypic testing and assay of gene function. Genome Res 11: $1246-1255$.

22. Bochner BR (2003) New technologies to assess genotype-phenotype relationships. Nat Rev Genet 4: 309-314.

23. Wimalasena TT, Greetham D, Marvin ME, Liti G, Chandelia Y, et al. (2014) Phenotypic characterisation of Saccharomyces spp. yeast for tolerance to stresses encountered during fermentation of lignocellulosic residues to produce bioethanol. Microb Cell Fact 13: 47.

24. Krishnan MS, Ho NW, Tsao GT (1999) Fermentation kinetics of ethano production from glucose and xylose by recombinant Saccharomyces 1400(pLNH33). Appl Biochem Biotechnol 77-79: 373-88.

25. Scheller HV, Ulvskov P (2010) Hemicelluloses. Annu Rev Plant Biol 61: 263-289.

26. Sjostrom B (1993) Wood polysaccharides. Academic Press, USA, 2: 51-70.

27. Mills TY, Sandoval NR, Gill RT (2009) Cellulosic hydrolysate toxicity and tolerance mechanisms in Escherichia coli. Biotechnol Biofuels 2: 26.

28. Ludovico P, Sousa MJ, Silva MT, Leão C, Côrte-Real M (2001) Saccharomyces cerevisiae commits to a programmed cell death process in response to acetic acid. Microbiology 147: 2409-2415.

29. Hengartner MO (2000) The biochemistry of apoptosis. Nature 407: 770-776.

30. Matsuyama S, Reed JC (2000) Mitochondria-dependent apoptosis and cellular $\mathrm{pH}$ regulation. Cell Death Differ 7: 1155-1165.

31. (1977) Reaction-products of yeast fermentations. Process Biochemistry 12: 19-21.

32. Pagliardini J, Hubmann G, Alfenore S, Nevoigt E, Bideaux C, et al. (2013) The metabolic costs of improving ethanol yield by reducing glycerol formation capacity under anaerobic conditions in Saccharomyces cerevisiae. Microb Cell Fact 12: 29.

33. Ding J, Bierma J, Smith MR, Poliner E, Wolfe C, et al. (2013) Acetic acid inhibits nutrient uptake in Saccharomyces cerevisiae: auxotrophy confounds the use of yeast deletion libraries for strain improvement. Appl Microbiol Biotechnol 97 7405-7416. 